\title{
Phylogenetic grouping and virulence characterization of ESBL-producing and non-producing vaginal Escherichia coli
}

\author{
Sareaa Maseer Gatya Al-Mayahie \\ Microbiology, Department of Biology, College of Science, University of Wasit, Al-Kut, Wasit Province, Iraq \\ Email address: \\ sareaamaseer@yahoo.com
}

\section{To cite this article:}

Sareaa Maseer Gatya Al-Mayahie. Phylogenetic Grouping and Virulence Characterization of ESBL-Producing and Non-Producing Vaginal Escherichia Coli. American Journal of Biomedical and Life Sciences. Vol. 2, No. 5, 2014, pp. 127-133. doi: 10.11648/j.ajbls.20140205.14

\begin{abstract}
The initial colonization of the vaginal mucosa with Escherichia coli is considered as a critical step toward urinary tract and neonatal infections. This study was conducted to characterize ESBL-producing (n=40) vaginal $E$. coli isolates from pregnant and non-pregnant women. These isolates were compared with corresponding ESBL-non-producing E. coli isolates $(n=21)$. Both groups were investigated using PCR-based protocols for their phylogenetic origin and virulence genotype. High numbers of ESBL producers and non-producers were from group B2 (47.5\% vs. 42.8\%, respectively). None of ESBL nonproducers clustered in group $\mathrm{D}$, whereas significant numbers $(\mathrm{P} \leq 0.05)$ of them belonged to group B1 (33.3\%) in comparison with $20.0 \%$ and $7.5 \%$ of ESBL producers, respectively. Significant differences in the prevalence of this study included virulence factors were not observed between these two groups. In both high rates of multiple virulence factors possession were demonstrated among isolates belonged to groups B2 and D. Comparison of CTX-M-producers with non-CTX-M-ESBLproducers and ESBL-non-producers revealed no significant differences among these three groups. In total, 60.8\%, 17.3\%, $17.3 \%$ and $4.3 \%$ of multidrug resistant (MDR) isolates clustered in groups B2, D, A and B1, respectively. All MDR-ESBL-non producers $(100 \%)$ belonged to phylogroup B2 compared with 50\% of MDR ESBL-producers and their virulence was much more higher. This study indicates that significant differences are not present between ESBL-producing and non-producing vaginal $E$. coli for both phylogenetic group distribution and virulence genes possession. Also, ESBL-producing vaginal $E$. coli, especially CTX-M producers, tend to be more dominant among the highly virulent phylogroup B2 and to a lesser extent group D. These data reveal the importance of vaginal colonization by these highly virulent, MDR, ESBL-producing E. coli as a source of extraintestinal E. coli infections.
\end{abstract}

Keywords: Vaginal E. Coli, ESBL Producers, Virulence, Phylogroups

\section{Introduction}

Vaginal colonization by Escherichia coli was documented as a source of other extraintestinal E. coli infections in both women and their contacts, such as urinary tract infections (UTIs) [1] and neonatal infections [2]. In addition, sexual transmission of $E$. coli between partners was reported [3]. Vaginal E. coli was also reported as one of the predominant microorganisms in cases of aerobic vaginitis [4-6]. In theory, aerobic vaginitis may be a better candidate than bacterial vaginosis as the cause of pregnancy complications, such as ascending chorioamnionitis, preterm rupture of the membranes and preterm delivery [4]. An extensive analyses of phylogenetic group and virulence factors of $E$. coli isolated from females reproductive tract infection (RTI) were carried out [7-10]. In these studies, it was found that vaginal $E$. coli have unique properties that may enhance their virulence. These properties are similar to those associated with other extraintestinal pathogenic $E$. coli, where most of them were derived from phylogroups B2 and D and possess numerous virulence factors such as adhesins, toxins, siderophores and polysaccharide coatings.

Extended-spectrum beta-lactamases (ESBLs) are a group of enzymes mediating resistance to most beta-lactams, including expanded-spectrum cephalosporins but excluding carbapenems and cephamycins. These enzymes are now widely distributed worldwide in Gram-negative bacteria (particularly in Enterobacteriaceae) with a specific and still 
growing expansion of those of the CTX-M type. There are also increasing reports of ESBL-producing clinical isolates expressing multidrug resistance (MDR) [11-12]. As the relationship of bacterial virulence and antimicrobial resistance still controversial and as vaginal $E$. coli is considered as a source of extraintestinal pathogenic E. coli, this study was performed to investigate the phylogenetic origin and extraintestinal pathogenic E. coli virulence factors' prevalence among well characterized ESBL-producing vaginal $E$. coli isolates from pregnant and non-pregnant women in comparison with those that are ESBL nonproducers.

\section{Materials and Methods}

\subsection{Bacterial Isolates}

This study included well characterized ESBL-producing $(\mathrm{n}=40)$ and non-producing $(\mathrm{n}=21)$ vaginal $E$. coli isolates from pregnant $(\mathrm{n}=23)$ and non-pregnant $(\mathrm{n}=38)$ women, aged 18-45 years. Isolation, identification, and ESBL production and multidrug resistance of these isolates were reported in previous work [13].

\subsection{DNA Preparation for PCR}

Each isolate was subcultured on tryptic soy agar plate for $24 \mathrm{~h}$ at $37^{\circ} \mathrm{C}$. From the agar plate, 5 colonies were picked and suspended in $100 \mu \mathrm{l}$ sterile distilled water. Bacterial suspensions were run for $10 \mathrm{~min}$ at $94^{\circ} \mathrm{C}$ [14] in a DNA thermocycler (MultiGene, Labnet International, Inc., USA) and cell debris were removed by centrifugation $(12,000 \mathrm{rpm}$ for $1 \mathrm{~min})$. Five $\mu \mathrm{l}$ of supernatant was used as a template DNA in PCR.

\subsection{Phylogenetic Grouping of the Isolates}

As a first step, the isolates were classified using the rapid phylogenetic grouping technique described by Clermont et al. [15]. This method is based on a triplex PCR involving the amplification of two genes (chuA and yjaA) and of an anonymous fragment of DNA from E. coli. Briefly, PCR was performed with three primer pairs, in a total volume of $25 \mu \mathrm{l}$ containing $12.5 \mu \mathrm{l}$ of KapaTaq 2x Ready Mix (KAPA Biosystems, USA), 20 pmol concentrations of each primer, and $5 \mu \mathrm{l}$ of DNA template. The PCR conditions were as follows: denaturation for $4 \mathrm{~min}$ at $94^{\circ} \mathrm{C}, 30$ cycles of $5 \mathrm{~s}$ at $94^{\circ} \mathrm{C}$ and $10 \mathrm{~s}$ at $59^{\circ} \mathrm{C}$, and a final extension step of $5 \mathrm{~min}$ at $72^{\circ} \mathrm{C}$.

In the second step, a multiplex PCR was performed for isolates with a standard protocol described by Clermont et al. [15], under the following conditions: denaturation for $5 \mathrm{~min}$ at $94^{\circ} \mathrm{C} ; 30$ cycles of $30 \mathrm{~s}$ at $94^{\circ} \mathrm{C}, 30 \mathrm{~s}$ at $55^{\circ} \mathrm{C}$, and $30 \mathrm{~s}$ at $72^{\circ} \mathrm{C}$; and a final extension step of $7 \mathrm{~min}$ at $72^{\circ} \mathrm{C}$.

For each isolate, these two steps were repeated at least twice and phylogeny was performed by combining the results of both protocols. The results were interpreted as follows, according to Clermont et al. (2000): group B2 (chuA+, yjaA+,
TspE.C2 \pm ), group D (chuA+, yjaA-, TspE.C2 \pm ), group B1 (chuA-, yjaA \pm , TspEC $2+)$ and group $\mathrm{A}($ chuA-, yjaA \pm , TspE.C2-).

\subsection{Genotypic Virulence Characterization of the Isolates}

Multiplex PCR was used to detect six genes encoding virulence determinants usually associated with the $E$. coli strains responsible for extraintestinal infections: fim $H$ (type 1 pili), papC (type $\mathrm{P}$ pili), sfa/foc (type $\mathrm{S}$ pili and type $1 \mathrm{C}$ fimbriae), hly (alpha-hemolysin), iucC (aerobactin), and $n e u C$ (K1 capsule antigen) [16, 17]. Virulence factor genes were amplified with the primers described elsewhere $[14,18$ $21]$, in a total volume of $50 \mu \mathrm{L}$ containing $25 \mu \mathrm{L}$ of KapaTaq 2x Ready Mix (KAPA Biosystems, USA), 20 pmol concentrations of each primer except hly (30 pmol), and $5 \mu \mathrm{L}$ of DNA template [14]. The reaction conditions were as follows [18]: initial denaturation at $94^{\circ} \mathrm{C}$ for $5 \mathrm{~min}$ followed by 25 cycles of denaturation at $94^{\circ} \mathrm{C}$ for $30 \mathrm{~s}$, annealing at $63^{\circ} \mathrm{C}$ for $30 \mathrm{~s}$, and extension at $68^{\circ} \mathrm{C}$ for $3 \mathrm{~min}$, followed by a final 10 -min extension period at $72^{\circ} \mathrm{C}$. The amplification products were separated by electrophoresis in a $2 \%$ agarose gel containing ethidium bromide. A 100-bp DNA ladder (Kappa Universal, USA) was used in each gel as a molecular size marker.

\subsection{Statistical Analysis}

The $x^{2}$ test was used for statistical comparison of groups; values $<0.05$ were regarded as significant [22].

\section{Results}

In previous work [13] we found that 40 out of $61(65.5 \%)$ of vaginal $E$. coli isolates from pregnant and non-pregnant women were ESBL producers. In the current study these isolates were investigated using PCR-based protocols for their phylogenetic origin and virulence genotype, targeting 6 virulence genes, in comparison with ESBL non-producers. High numbers of ESBL producers and non-producers were from group B2 (47.5\% vs. 42.8\%, respectively) (Table 1). None of ESBL non-producers clustered in group D, whereas significant numbers $(\mathrm{P} \leq 0.05)$ of them belonged to group $\mathrm{B} 1$ (33.3\%) compared with $20.0 \%$ and $7.5 \%$ of ESBL producers, respectively.

Significant differences in the prevalence of this study included virulence factors were not observed among isolates belonged to these two groups (Table 2).

The frequency of virulence genes according to phylogroup is shown in Table 3. In both ESBL producers and nonproducers high rates of multiple virulence factors possession (three or more virulence factors/ isolate) were demonstrated among isolates belonged to groups B2 (73.6 \% vs. 100\%, respectively), D (50.0\%, only in ESBL producers), and group A (10.0\%, only in ESBL producers). While none of isolates belonged to groups A (in ESBL non-producers) and B1 had multiple virulence factors. 
Table 1. Phylogroup distribution of ESBL-producing and non-producing vaginal E. coli isolates from pregnant and non-pregnant women.

\begin{tabular}{|c|c|c|c|c|c|}
\hline \multirow{2}{*}{ Study Group } & & \multicolumn{4}{|c|}{ No. (\%) of isolates positive for the indicated phylogenetic group } \\
\hline & & $\mathbf{A}$ & B1 & B2 & D \\
\hline \multirow{3}{*}{ ESBL producers } & Pregnant women's isolates $(\mathrm{n}=17)$ & $4(23.5)$ & $2(11.7)$ & $8(47.0)$ & $3(17.6)$ \\
\hline & Non-pregnant women's isolates $(\mathrm{n}=23)$ & $6(26.0)$ & $1(4.3)$ & $11(47.8)$ & $5(21.7)$ \\
\hline & Total $(n=40)$ & $10(25.0)$ & $3(7.5)$ & $19(47.5)$ & $8(20.0)$ \\
\hline \multirow{3}{*}{ ESBL non-producers } & Pregnant women's isolates $(\mathrm{n}=6)$ & $2(33.3)$ & $2(33.3)$ & $2(33.3)$ & 0 \\
\hline & Non-pregnant women's isolates $(\mathrm{n}=15)$ & $3(20.0)$ & $5(33.3)$ & $7(46.6)$ & 0 \\
\hline & Total $(n=21)$ & $5(23.8)$ & $7(33.3)$ & $9(42.8)$ & 0 \\
\hline Total $(n=61)$ & & $15(24.5)$ & $10(16.3)$ & $28(45.9)$ & $8(13.1)$ \\
\hline
\end{tabular}

Table 2. Virulence genotypes of ESBL-producing and non-producing vaginal E. coli isolates from pregnant and non-pregnant women.

\begin{tabular}{|c|c|c|c|c|c|c|c|}
\hline \multirow{2}{*}{ Study Group } & & \multicolumn{6}{|c|}{ No. $(\%)$ of isolates positive for the indicated virulence gene } \\
\hline & & fimH & papC & $s f a / f o c$ & hly & iucC & neuC \\
\hline \multirow{3}{*}{ ESBL producers } & Pregnant women's isolates $(\mathrm{n}=17)$ & $15(88.2)$ & $8(47.0)$ & $4(23.5)$ & $6(35.2)$ & $12(70.5)$ & $6(35.2)$ \\
\hline & Non-pregnant women's isolates $(\mathrm{n}=23)$ & $21(91.3)$ & $8(34.7)$ & $4(17.3)$ & $6(26.0)$ & $12(52.1)$ & $6(26.0)$ \\
\hline & Total $(n=40)$ & $36(90.0)$ & $16(40.0)$ & $8(20.0)$ & $12(30.0)$ & $24(60.0)$ & $12(30.0)$ \\
\hline \multirow{3}{*}{ ESBL non-producers } & Pregnant women's isolates $(\mathrm{n}=6)$ & $6(100)$ & $2(33.3)$ & $1(16.6)$ & $2(33.3)$ & $3(50.0)$ & $1(16.6)$ \\
\hline & Non-pregnant women's isolates $(\mathrm{n}=15)$ & $15(100)$ & $7(46.6)$ & $5(33.3)$ & $6(40.0)$ & $6(40.0)$ & $3(20.0)$ \\
\hline & Total $(n=21)$ & $21(100)$ & $9(42.8)$ & $6(28.5)$ & $8(38.0)$ & $9(42.8)$ & $4(19.0)$ \\
\hline Total $(\mathrm{n}=61)$ & & 57 (93.4) & 25 (40.9) & 14 (22.9) & $20(32.7)$ & $33(54.0)$ & $16(26.2)$ \\
\hline
\end{tabular}

Table 3. Phylogenetic group distribution of virulence genes among ESBL-producing and non-producing vaginal E. coli isolates.

\begin{tabular}{|c|c|c|c|c|c|c|c|}
\hline \multirow{2}{*}{ Study Group } & \multirow{2}{*}{ Phylogroup (no. of isolates) } & \multicolumn{6}{|c|}{ No. (\%) of isolates positive for the indicated virulence gene } \\
\hline & & fimH & papC & sfa/foc & hly & iucC & neuC \\
\hline \multirow{4}{*}{ ESBL producers $(n=40)$} & $A(n=10)$ & $8(80.0)$ & $1(10.0)$ & 0 & 0 & $6(60.0)$ & $1(10.0)$ \\
\hline & B1 $(n=3)$ & $2(66.6)$ & 0 & 0 & 0 & $1(33.3)$ & $1(33.3)$ \\
\hline & $\mathrm{B} 2(\mathrm{n}=19)$ & $18(94.4)$ & $11(57.8)$ & $8(42.1)$ & $11(57.8)$ & $14(73.6)$ & $8(42.1)$ \\
\hline & $\mathrm{D}(\mathrm{n}=8)$ & $8(100.0)$ & $4(50.0)$ & 0 & $1(12.5)$ & $3(37.5)$ & $2(25.0)$ \\
\hline \multirow{4}{*}{ ESBL non-producers $(n=21)$} & $A(n=5)$ & $5(100.0)$ & 0 & 0 & 0 & $1(20.0)$ & 0 \\
\hline & $\mathrm{B} 1(\mathrm{n}=7)$ & $7(100.0)$ & 0 & 0 & 0 & $2(28.5)$ & $1(14.2)$ \\
\hline & $\mathrm{B} 2(\mathrm{n}=9)$ & $9(100.0)$ & $9(100)$ & $6(66.6)$ & $8(88.8)$ & $6(66.6)$ & $3(33.3)$ \\
\hline & $\mathrm{D}(\mathrm{n}=0)$ & 0 & 0 & 0 & 0 & 0 & 0 \\
\hline
\end{tabular}

Comparison of CTX-M-producers with non-CTX-MESBL-producers and ESBL-non-producers revealed that there were no significant differences among these three groups regarding the possession of all studied traits except for papC of which CTX-M-producers and ESBL-nonproducers had significantly $(\mathrm{P} \leq 0.05)$ higher prevalence (48.3\% and $42.8 \%$, respectively) than non-CTX-M-ESBL- producers (11.1\%) (Table 4). High rates of multiple virulence factors possession were demonstrated only among isolates belonged to group B2 in both CTX-M producers $(73.3 \%)$ and ESBL non-producers $(100 \%)$ and group D $(71.4 \%$, only in CTXM producers), whereas none of isolates belonged to groups A and B1 had multiple virulence factors.

Table 4. Phylogenetic group and virulence genotypes of CTX-M-producing vaginal E. coli isolates in comparison with non-CTX-M-ESBL-producing and nonESBL-producing isolates.

\begin{tabular}{lllll}
\hline \multirow{2}{*}{ Traits } & & \multicolumn{2}{l}{ No. $(\%)$ of isolates positive for the indicated trait } \\
\cline { 2 - 5 } & & CTX-M producers $(\mathbf{n}=\mathbf{3 1})$ & Non-CTX-M ESBL producers (n=9) & ESBL non-producers (n=21) \\
\hline \multirow{4}{*}{ Phylogenetic group } & A & $6(19.3)$ & $4(44.4)$ & $5(23.8)$ \\
& B1 & $2(6.4)$ & $1(11.1)$ & $7(33.3)$ \\
& B2 & $16(51.6)$ & $3(33.3)$ & $9(42.8)$ \\
virulence gene & D & $7(22.5)$ & $1(11.1)$ & 0 \\
& fimH & $28(90.3)$ & $8(88.8)$ & $21(100)$ \\
& papC & $15(48.3)$ & $1(11.1)$ & $9(42.8)$ \\
& Sfalfoc & $6(19.3)$ & $2(22.2)$ & $6(28.5)$ \\
& hly & $9(29.0)$ & $3(33.3)$ & $8(38.0)$ \\
& iucC & $21(67.7)$ & $3(33.3)$ & $9(42.8)$ \\
\hline
\end{tabular}


Table 5. Phylogenetic group and virulence genotypes of multidrug resistant ESBL-producing and non--producing vaginal E. coli isolates.

\begin{tabular}{lllll}
\hline \multirow{2}{*}{ Traits } & \multicolumn{5}{l}{ No. (\%) of isolates positive for the indicated trait } \\
\cline { 2 - 5 } & MDR-ESBL producers (n=18/32: 56.2\%) & MDR-ESBL Non- producers (n=5/19: 26.3\%) & Total (n=23) \\
\hline \multirow{4}{*}{ Phylogenetic group } & A & $4(22.2)$ & 0 & $4(17.3)$ \\
& B1 & $1(5.5)$ & 0 & $1(4.3)$ \\
& B2 & $9(50.0)$ & $5(100)$ & $14(60.8)$ \\
& D & $4(22.2)$ & 0 & $4(17.3)$ \\
virulence gene & fimH & $18(100)$ & $5(100)$ & $23(100)$ \\
& papC & $10(55.5)$ & $5(100)$ & $15(65.2)$ \\
& Sfalfoc & $3(16.6)$ & $3(60.0)$ & $6(26.0)$ \\
& hly & $5(27.7)$ & $5(100)$ & $10(43.4)$ \\
& iucC & $14(77.7)$ & $4(80.0)$ & $18(78.2)$ \\
\hline
\end{tabular}

MDR: multidrug resistant; ESBL: extended-spectrum $\beta$-lactamase.

Multidrug resistance was higher among ESBL producers $(56.2 \%)$ than among ESBL non-producers (26.3\%). In total, $60.8 \%, 17.3 \%, 17.3 \%$ and $4.3 \%$ of MDR isolates clustered in groups B2, D, A and B1, respectively (Table 5). All MDRESBL-non producers $(100.0 \%)$ belonged to phylogroup B2 compared with $50.0 \%$ of MDR ESBL-producers. The two groups did not differ significantly for all of the studied virulence factors, except for hly which was significantly more prevalent among all (100\%) MDR-ESBL-non producers than among MDR-ESBL producers $(27.7 \%)$.

\section{Discussion}

In previous studies [23-28] the relationship between ESBL production and bacterial virulence was extensively analyzed for ExPEC isolates from different clinical cases, specially uropathogenic E. coli (UPEC). As vaginal E. coli may be a source of clinically important ExPEC (recurrent UTI, neonatal meningitis and septicemia, and aerobic vaginitis) and as a result of unavailability of studies dealing with this subject among vaginal $E$. coli, results of this study were discussed in comparison with results of previous studies that dealt with ESBL-producing ExPEC isolates ,especially UPEC and Bacteremic E. coli.

In total, the pattern of phylogroup distribution and virulence factor prevalence in this study included vaginal $E$. coli isolates was consistent with others [7-10]. A significant numbers of them clustered in group B2 (45.9\%) (Table 1) and high percent of them showed high prevalence of ExPEC virulence genes, especially $p a p C$, sfa/foc, and hly (Table 2), which are characteristic virulence factors of ExPEC [14, 18]. In addition, virulence genes concentrated among isolates clustered in group B2 and to a lesser extent group D. These results confirmed the pathogenic potential of vaginal $E$. coli from both pregnant and non-pregnant women and indicated the important role played by vaginal colonization with such isolates as a reservoir for other extraintestinal $E$. coli infections [8-9].

High numbers of ESBL producers and non-producers were from group B2 (47.5\% vs. $42.8 \%$, respectively). None of ESBL non-producers clustered in group D, whereas significant numbers $(\mathrm{P} \leq 0.05)$ of them belonged to group $\mathrm{B} 1$
(33.3\%) compared with $20.0 \%$ and $7.5 \%$ of ESBL producers, respectively. Previous studies have revealed a controversy regarding the phylogenetic distribution of ESBL-producing $E$. coli. In Turkey [29] ESBL-producing isolates distributed equally into phylogenetic groups B2 (30\%), D (35\%) and A $(35 \%)$. Whereas others $[28,30]$ observed that ESBL among E. coli clinical strains was associated with shifts in phylogenetic distribution toward non-B2 phylogenetic groups (A/B1 and D/A, respectively). In another study [25] it was found that most ESBL-producing $E$. coli isolates were derived from phylogenetic group D (63\%) whereas only $21 \%$ and $13 \%$ were from groups A and B2, respectively. These differences between our study and these studies and among these studies with each other may be due to the differences in resistance phenotype, especially ciprofloxacin resistance and ESBL type especially CTX-M subtypes [25, 30]. In our study $40.6 \%$ of ESBL producers were resistant to ciprofloxacin of which $46.1 \%$ were from group B2, compared with $23.1 \%$ of isolates clustered in each of groups D and A and only 7.6\% from B1. In addition, $92.3 \%$ of ciprofloxacin resistant isolates possessed CTX-M type ESBL alone or in combination with other types. Furthermore, $38.4 \%$ of ciprofloxacin resistant isolates with CTX-M-type ESBL were from group B2. So that our results were in contrast with those reached by Johnson et al. [30] who concluded that ciprofloxacin resistance was associated with greatly reduced inferred virulence and shifts away from the highly virulent phylogenetic group B2. While we agreed with Pitout et al. [25] who demonstrated that CTX-M subtype predicts phylogenetic background. Recent reports from all over the world claimed the spread of highly virulent E. coli ST131 clone (mainly from group B2) producing CTX-M-15 which characterized by multidrug resistance and co-production of OXA-1 or TEM-1b $\beta$-lactamases as well as aminoglycoside resistance genes aac(3')-IIa and aac(6')-Ib-cr (which also deactivates ciprofloxacin) on transferable plasmids [31-33].

Both ESBL producers and non-producers did not differ significantly for all of this study included virulence factors (Table 2). Similar results were obtained by others [29, 34]. In this study, ESBL producers and non-producers also had similar rates of multiple virulence factors possession which was demonstrated among isolates belonged to groups B2 
(73.6\% vs. $100 \%$, respectively), D (50\%, only in ESBL producers) and A (10\%, only in ESBL producers). These results were consistent with what is known about the concentration of virulence factors in isolates belonged to phylogroups B2 and D [35-36]. Similarly, it was reported that isolates belonging to phylogenetic groups B2 and D had more virulence factors than those belonging to $\mathrm{A}$ and $\mathrm{B} 1$, regardless of the ESBL-type they produced [26]. These virulence differences were attributed to phylogenetic differences in that the less virulent isolates were derived from low-virulence phylogenetic groups rather than because of resistance per se [23]. This suggests that the movement of the ESBL genes does not interfere significantly with the distribution of virulence factors within a particular phylogroup [37]. Hence the widespread dissemination of antibiotic resistance among bacterial populations has maintained or even increased the number of harmful bacteria involved in infections [38].

In the current work, most ESBL-producing isolates carried CTX-M-type ESBL (77.5\%), all of these CTX-M ESBLs belonged to subtype CTX-M-1. Of these isolates, $51.6 \%$ clustered in group B2 versus $33.3 \%$ of non-CTX-M ESBL producers and $42.8 \%$ of ESBL non-producers (Table 4). Also, similarities were apparent between the virulence factor profiles of the isolates of these three groups, except for papC which was significantly $(\mathrm{P} \leq 0.05)$ more prevalent among CTX-M producers and ESBL non-producers than among non-CTX-M ESBL producers (Table 4). This papC prevalence difference may be attributed to the higher distribution of phylogroup B2 (in which virulence factors are concentrated) among isolates of these two groups (51.6\% and $42.8 \%$, respectively) than among non-CTX-M ESBL producers $(33.3 \%)$. These findings were in agreement with Pitout et al. [25], Karisik et al. [26] and Zhang et al. [39], who reported that most $E$. coli with CTX-M ESBLs belonged to virulent phylogenetic groups, mainly B2 $(67.0 \%, 60.0 \%$, $75.0 \%$, respectively) and the prevalence of each virulence factor was also similar irrespective of $b l a_{\text {СТХ-M }}$ production [40]. Therefore, CTX-M production had no influence on virulence but was a major factor in clinical outcome [25]. However, this study results were in contrast with other studies [41-42] in which it was found that CTX-M-type ESBLs were mainly in $E$. coli strains with few virulence factors or in strains causing minor infections. Furthermore, 94.4\% of CTX-M producers in this study were multidrug resistant of which $47.0 \%$ belonged to group B2, whereas only $26.3 \%$ of ESBL non-producers were MDR. This multidrug resistance prevalence among B2 isolates was consistent with what was obtained by Nazir et al. [43] where they found that group B2 was significantly overrepresented among the multidrug resistant isolates (45.4\%). Similar reports were published elsewhere [26, 44-45]. This high prevalence of multidrug resistance among these highly virulent B2 group suggests that there may be features of the B2 phylogenetic type that have facilitated the acquisition of relevant resistance determinants, whether by mutation or by horizontally transmitted resistance genes. So that a particular, multidrug-resistant, B2 clone with high fitness had arisen and spread throughout the population [43].

Worldwide, the increased distribution of multidrug resistant bacteria is the most serious point in the problem of bacterial antibiotic resistance. This property is associated with ESBL production [11-12, 46] and make treatment of infections caused by ESBL-producing bacteria more and more difficult. Here in this work prevalence of MDR was higher among ESBL producers (56.2\%) than among ESBL non-producers $(26.3 \%)$. As a whole $60.8 \%, 17.3 \%, 17.3 \%$ and $4.3 \%$ of this study included MDR isolates (both ESBL producers and non-producers) clustered in groups B2, D, A, and $\mathrm{B} 1$, respectively (Table 5). In both MDR ESBL producers and non-producers the differences were not significant for all of the studied traits except for $h l y$ as all MDR ESBL non-producers belonged to phylogroup B2 (in which virulence factors are concentrated) compared with only $50.0 \%$ of MDR ESBL producers. Although the differences were not significant, MDR ESBL non-producers seemed to be more virulent than MDR ESBL producers, as all of them (100\%) belonged to group B2 versus $50.0 \%$ of MDR ESBL producers (Table 5). In addition, the rate of multiple virulence factors possession was higher among these isolates $(100 \%)$ in comparison with $61.1 \%$ of MDR ESBL producers. In another study [23] it was reported that MDR isolates were most prevalent in group $\mathrm{D}$, whereas prevalence in group B2 was the least and that the MDR isolates exhibited significantly lower prevalence of most of the screening VFs. So that the phylogenetic differences may accounted for the discrepancies between this study results and those obtained by Johnson et al. [23]. It was also reported that the presence of antibiotics increases the frequency of horizontal gene transfers 10- to 10,000-fold [47], thereby encouraging the horizontal transfer and recombination of virulence as well as antibiotic resistance genes [38]. These results revealed the potential pathogenicity of these isolates and required further investigation as the number of MDR non-ESBL-producers was small (only 5 isolates). These results also indicated the seriousness of infections caused by such highly virulent, MDR, ESBLproducing bacteria and stressed on the urged demand for alternative treatments of such infections and a worldwide policy to put a suitable measurements to control the spread of such MDR bacteria.

\section{Conclusion}

This study indicates that significant differences are not present between ESBL-producing and non-producing vaginal $E$. coli for both phylogenetic group distribution and virulence genes possession. Also, ESBL-producing vaginal E. coli, especially CTX-M producers, tend to be more dominant among the highly virulent phylogroup B2 and to a lesser extent group D. These data highlight the importance of vaginal colonization by these highly virulent, MDR, ESBLproducing $E$. coli as a source of extraintestinal E. coli infections. 


\section{Acknowledgments}

I am grateful to the college of Science/University of Wasit for supporting this research.

\section{References}

[1] Xie J, Foxman B, Zhang L, Marrs CF (2006) Molecular epidemiologic identification of Escherichia coli genes that are potentially involved in movement of the organism from the intestinal tract to the vagina and bladder. J Clin Microbiol (7): 2434-2441.

[2] Bonacorsi S, Bingen E (2005) Molecular epidemiology of Escherichia coli causing neonatal meningitis. Int $\mathrm{J}$ Med Microbiol 2(6-7): 373-381.

[3] Foxman B, Manning SD, Tallman P, Bauer R, Zhang L, Koopman JS, Gillespie B, Sobel JD, Marrs CF (2002) Uropathogenic Escherichia coli are more likely than commensal E. coli to be shared between heterosexual sex partners. Am J Epidemiol 1(12):1133-1140.

[4] Donders GGG, Vereecke A, Bosman E, Dekeersmaecker A, Salembier G, Spitz B (2003) Definition of a type of abnormal vaginal flora that is distinct from bacterial vaginosis: aerobic vaginitis. Inter J Obstet Gynecol 1(1): 34-43.

[5] French L, Horton J, Matousek M (2004) Abnormal vaginal discharge: using office diagnostic testing more effectively. J Family Practice (10): 1-13.

[6] Donders GGG (2007) Definition and classification of abnormal vaginal flora. Best Practice \& Res Clin Obstet Gynecol (3): 355-373.

[7] Cook SW, Hammill HA, Hull A (2001) Virulence factors of Escherichia coli isolated from female reproductive tract infections and neonatal sepsis. Infect Dis Obstet Gynecol 9: 203-207.

[8] Obata-Yasuka M, Ba-Thein W, Tsukamoto T, Yoshikawa H, Hayashi H (2002) Vaginal Escherichia coli share common virulence factor profiles, serotypes and phylogeny with other extraintestinal E. coli. Microbiol 148: 2745-2752.

[9] Watt S, Lanotte P, Mereghetti L, Moulin-Schouleur M, Picard B, Quentin R (2003) Eschierichia coli strains from pregnant women and neonates: intraspecies genetic distribution and prevalence of virulence factors. J Clin Microbiol (5): 19291935 .

[10] Usein C-R, Grigore LA, Georgescu RM, Bãltoiu MC, Condei M, Teleman MD (2011) Phylogenetic background and extraintestinal virulence genotypes of Escherichia coli vaginal strains isolated from adult women. Revista Română de Medicină de Laborator (1/4): 37-45.

[11] Chen LF, Choppra T, Kaye KS: Pathogens resistant to antibacterial agents (2009) Infec Dis Clin N Am 23: 817-845.

[12] Livermore DM (2012) Current epidemiology and growing resistance of gram-negative pathogens. Korean J Intern Med 27(2): 128-142.

[13] Al-Mayahie SMG (2013) Phenotypic and genotypic comparison of ESBL production by vaginal Escherichia coli isolates from pregnant and non-Pregnant women. Ann Clin
Microbiol Antimicrob 12: (7).

[14] Yamamoto S, Terai A, Yuri K, Kurazono H, Takeda Y, Yoshida O (1995) Detection of urovirulence factors in Escherichia coli by multiplex polymerase chain reaction. FEMS Immunol Med Microbiol 12: 85-90.

[15] Clermont O, Bonacorsi S, Bingen E (2000) Rapid and simple determination of the Escherichia coli phylogenetic group. Appl Environ Microbiol 66: 4555-4558.

[16] Johnson JR, Owens K, Gajewski A, Kuskowski MA (2005) Bacterial characteristics in relation to clinical source of Escherichia coli isolates from women with acute cystitis or pyelonephritis and uninfected women. J Clin Microbiolo (12): 6064-6072.

[17] Lane MC, Mobley HLT (2007) Role of P-fimbrial-mediated adherence in pyelonephritis and persistence of uropathogenic Escherichia coli (UPEC) in the mammalian kidney. Kidney Inter (1): 19-25.

[18] 18. Johnson JR, Stell AL (2000) Extended virulence genotypes of Escherichia coli strains from patients with urosepsis in relation to phylogeny and host compromise. J Infect Dis 181: 261-272.

[19] Le Bouguenec C, Archambaud M, Labigne A (1992) Rapid and specific detection of the pap, afa, and sfa adhesinencoding operon in uropathogenic Escherichia coli strains by polymerase chain reaction. J Clin Microbiol 30: 1189-1193.

[20] Bingen, E, Bonacorsi S, Brahimi N, Denamur E, Elion J (1997) Virulence patterns of Escherichia coli K1 strains associated with neonatal meningitis. J Clin Microbiol 35:2981-2982.

[21] Zapata G, Crowley JM, Vann WF (1992) Sequence and expression of the Escherichia coli neuC gene product. J Bacteriol 174: 315-319.

[22] Ross SM (2009) Introduction to probability and statistics for Engineers and Scientists, 4th ed. Elsevier, London.

[23] Johnson JR, Kuskowski MA, Gajewski A, Sahm DF, Karlowsky JA (2004) Virulence characteristics and phylogenetic background of multidrug-resistant and antimicrobial-susceptible clinical isolates of Escherichia coli from across the United States, 2000-2001. J Infect Dis 190:1739-1744.

[24] Branger C, Zamfir O, Geoffroy S, Laurans G, Arlet G, Thien HV, Gouriou S, Picard B, Denamur E (2005) Genetic background of Escherichia coli and xtendedspectrum $\beta$ lactamase type. Emerg Infect Dis (1): 54-61.

[25] Pitout JDD, Laupland KB , Church DL , Menard ML , Johnson J R (2005) Virulence factors of Escherichia coli isolates that produce CTX-M-type extended-spectrum $\beta$ lactamases. Antimicrob Agents Chemother 49: 4667-4670.

[26] Karisik E, Ellington MJ, Livermore DM, Woodford N (2008) Virulence factors in Escherichia coli with CTX-M-and other extended-spectrum $\beta$-lactamases in the UK. J Antimicrob Chemother 61: 54-58.

[27] Kim CS, Kim ME, Cho Y-H, Cho IR, and Lee G (2010) Virulence characteristics and phylogenetic background of ciprofloxacin resistant Escherichia coli in the urine samples from korean women with acute uncomplicated cystitis. J Korean Med Sci 25: 602-607. 
[28] Rodri'guez-Baño J, Mingorance J, Ferna'ndez-Romero N, Serrano L, Lo' pez-Cerero L, Pascual A, the ESBL-REIPI group (2012) Virulence profiles of bacteremic extendedspectrum $\beta$-Lactamase-producing Escherichia coli: association with epidemiological and clinical features. PLOS ONE 7 (9): e44238.

[29] Yumuk Z, Afacan G, Nicolas-Chanoine M-H, Sotto A, Lavigne J-P (2008) Turkey: a further country concerned by community-acquired Escherichia coli clone O25ST1producing CTX-M-15. J Antimicrob Chemother 62: 284288.

[30] Johnson JR, Kuskowski MA, O'Bryan TT, Colodner R, Raz R (2005). Virulence genotype and phylogenetic origin in relation to antibiotic resistance profile among Escherichia coli urine sample isolates from Israeli women with acute uncomplicated cystitis. Antimicrobiol Agents Chemother (1): 26-31.

[31] Peirano G, Pitout JDD (2010). Molecular epidemiology of Escherichia coli producing CTX-M $\beta$-lactamases: the worldwide emergence of clone ST1O25:H4. International J Antimicrob Agents 35(4):316-321.

[32] Rogers BA, Sidjabat HE, Paterson DL (2011). Escherichia coli O25b-ST131: a pandemic, multiresistant, communityassociated strain. J Antimicrob Chemother 66(1):1-14.

[33] Cantón R, González-Alba JM, Galán JC (2012). CTX-M enzymes: origin and diffusion. Frontiers in Microbiol 2012, $3: 1-19$.

[34] Li S, Qu Y, Hu D, Shi Y-x (2012) Comparison of extended spectrum $\beta$-lactamases producing Escherichia coli with nonESBLsproducing E.coli: drug-resistance and virulence. World J Emerg Med 3 (3): 208-212.

[35] Picard B, Sevali J, Gouriou S, Duriez P, Brahimi N, Bingen E Elion J, Denamur E (1999) The link between phylogeny and virulence in Escherichia coli extraintestinal infection. Infect Immun 67: 546-553.

[36] 36. Johnson JR, Delavari P, Kuskowski M, Stell AL (2001) Phylogenetic distribution of extraintestinal virulenceassociated traits in Escherichia coli. J Infect Dis 183: 78-88.

[37] Valat C, Auvray F, Forest K, Métayer V, Gay E, de Garam CP, Madec J-Y, Haenni M (2012) Phylogenetic grouping and virulence potential of extended-spectrum- $\beta$-lactamaseproducing Escherichia coli strains in cattle. Appl Environ Microbiol (13): 4677-4682.
[38] Martínez LJ, Baquero F (2002) Interactions among strategies associated with bacterial infection: pathogenicity, epidemicity, and antibiotic resistance. Clin Microbiol Rev (4): 647-679.

[39] Zhang L, Lü X, Zong Z (2013) The emergence of blaCTX-M15-carrying Escherichia coli of ST1and new sequence types in Western China. Ann Clin Microbiol Antimicrob 12: 35

[40] Yu JK , Park K , Oh E-J , Kim S-Y, Park Y-J (2010) Phylogenetic groups and virulence factors in pathogenic and commensal strains of Escherichia coli and their association

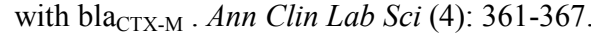

[41] Branger C, Zamfir O, Geoffroy S, Laurans G, Arlet G, Thien HV, Gouriou S, Picard B, and Denamur E (2005) Genetic background of Escherichia coli and extended-spectrum $\beta$ lactamase type. Emerg Infect Dis 11: 54-61.

[42] Brigante G, Luzzaro F, Perilli M, Lombardi G, Coli A, Rossolini GM, Amicosante G, Toniolo A (2005) Evolution of CTX-M-type $\beta$-lactamases in isolates of Escherichia coli infecting hospital and community patients. Int J Antimicrob Agents 25: 157-162.

[43] Nazir H, Cao S, Hasan F, Hughes (2011) Can phylogenetic type predict resistance development? J Antimicrob Chemother 66: 778-787.

[44] Park SH, Byun, JH, ChoiS-M, Lee, D-G, Kim S-H, Kwon, J-C, Park C, Choi J-H, Yoo J-H (2012) Molecular epidemiology of extended-spectrum $\beta$-lactamase-producing Escherichia coli in the community and hospital in Korea: emergence of ST1producing CTX-M-15. BMC Infectious Diseases 12:149.

[45] Ahmed MYA (2013) Characterization and Molecular Epidemiology of Extended-Spectrum- $\beta$-Lactamase-Producing Escherichia coli derived from University Hospitals of Egypt and Germany. Inaugural Dissertation, Faculty of Medicine, of the Justus-Liebig-University Giessen, Germany.

[46] Paterson DL, Bonomo RA (2005) Extended-spectrum $\beta$ lactamases: a clinical update. Clin Microbiol Rev (4): 657-686.

[47] Ho M-W, Traavik T, Olsvik O, Midtvedt T, Tapperser B, Howard VC, von Weizsacker C, McGavin GC (1998) Gene technology in the etiology of drug-resistant diseases. Third World Network and the Ecologist (based in the United Kingdom). Third World Network Penang, Malaysia, PP.1-72. 